\title{
Experience at the Department of Pediatrics of a private facility in the Metropolitan Area of Buenos Aires during the COVID-19 pandemic
}

\author{
Daniel R. Capra, M.D. ${ }^{a}$, Gabriela Ucha, M.D. ${ }^{a}$, Enrique Antoni, M.D. ${ }^{a}$, \\ Augusto Malfetano, M.D. ${ }^{a}$, Nelson Wolfsteiner, M.D. ${ }^{a}$, Pilar Arias, M.D. ${ }^{b}$ and \\ Fabiana García, M.D.c
}

\begin{abstract}
Introduction. Towards the end of 2019, a novel coronavirus that causes COVID-19 was identified and became a pandemic. In Argentina, approximately $37 \%$ of the total population lives in the Metropolitan Area of Buenos Aires (AMBA), where most cases have been diagnosed. The objective of this study was to describe the clinical and epidemiological characteristics of COVID-19 patients and the impact on the operations of the Department of Pediatrics of a private facility located in the AMBA.

Methods. Retrospective, observational study conducted at a facility in the west of AMBA between March 12 $2^{\text {th }}$ and August 31 ${ }^{\text {st }}, 2020$. All patients younger than 16 years diagnosed with COVID-19 were included. Demographic, epidemiological, and clinical characteristics; indication for hospitalization/outpatient followup; number of outpatient visits; hospitalization due to seasonal viral infections; staff on leave; changes in bed availability and health care providers' activities were recorded.

Results. There were 5454 pediatric outpatient visits, COVID-19 was suspected in 753/5454 (13.8 \%) and 152/753 (20.2 \%) were confirmed cases. Their median age was 82 months (interquartile range: $20.5-147$ months); $50 \%$ were males. Fever was the most common symptom. In total, 22/152 (14.5\%) patients were hospitalized. Outpatients visits decreased by $87 \%$; there were nohospitalizations due to seasonal viral infections; and $52.9 \%(91 / 172)$ of staff took a leave.

Conclusions. Most cases were mild, and fever was the main symptom. The department operations were considerably affected in terms of human resources. It is worth noting the need for a logistic organization at the Department of Pediatrics to face such contingency.

Key words: COVID-19, pediatrics, Metropolitan Area of Buenos Aires, private hospitals, human resources.
\end{abstract}

http: / / dx.doi.org/10.5546/ aap.2021.eng.310

Daniel R. Capra, M.D.: dcapra@hotmail.com

Funding:

None.

Conflict of interest: None.

Received: $11-10-2020$ Accepted: 3-8-2021
To cite: Capra DR, Ucha G, Antoni E, Malfetano A, et al. Experience at the Department of Pediatrics of a private facility in the Metropolitan Area of Buenos Aires during the COVID-19 pandemic. Arch Argent Pediatr 2021;119(5):310-316.

\section{INTRODUCTION}

Towards the end of December 2019, several cases of viral pneumonia were detected in Wuhan, in the province of Hubei in the People's Republic of China. ${ }^{1}$ A novel coronavirus was identified and sequenced, now known as SARS-CoV-2, which causes the disease called COVID-19. ${ }^{2}$

The subsequent worldwide dissemination became a major challenge for public health.

In Argentina, an epidemiological alert was released on January $22^{\text {nd }}$, 2020 and surveillance was initiated. On March $3^{\text {rd }}$, the first COVID-19 case was confirmed and, on March $7^{\text {th }}$, the Ministry of Health reported the first death in Argentina and Latin America. ${ }^{3-5}$

On March 11 ${ }^{\text {th }}$, 2020, the World Health Organization (WHO) officially declared that COVID-19 had reached the pandemic status. ${ }^{6}$

Until October 20 $0^{\text {th }}, 2020,40118333$ cases and 1114749 deaths had been reported globally. ${ }^{7}$

In Argentina, until October $20^{\text {th }}$, 2020, 1018999 cases and 27100 deaths had been reported. ${ }^{8}$

The Metropolitan Area of Buenos Aires (AMBA) encompasses the Autonomous City of Buenos Aires and some districts of Greater Buenos Aires (40 municipalities). The AMBA is home to the highest population density of Argentina, with $37 \%$ of the country's total population. ${ }^{9}$

The greatest number of cases were diagnosed in the AMBA: 648 628, which account for $63.65 \%$ of all the 
country's cases. ${ }^{8}$ In the pediatric population (children and adolescents younger than 19 years), to the same date, a total of $87489(8.6 \%)$ cases were reported across the country, all of whom had a mild-moderate course. ${ }^{10}$

The objective of this study was to describe the clinical and epidemiological characteristics of patients diagnosed with COVID-19 and describe the impact on the operations of a Department of Pediatrics located in the AMBA.

\section{MATERIAL AND METHODS}

Study design: Retrospective, observational.

Setting: The facility is located in the western area of the AMBA, in the city of Ramos Mejía, corresponding to the municipality of La Matanza, and has a total of 250 beds.

The Department of Pediatrics has 44 beds: 32 for general care and 12 for intensive care, and is prepared to provide care for patients with complex pathologies (cancer; major surgeries, such as neurosurgery, chest surgery, severe trauma). It does not perform cardiovascular surgery or organ or tissue transplants.

Inclusion criteria: All children seen at the facility who were younger than 16 years and had a diagnosis of COVID-19 confirmed by polymerase chain reaction (PCR) swab test.

Data collection and analysis: The following data were collected at the time of completing the medical record: population demographic characteristics (age and sex), epidemiological characteristics of the group sharing the household (confirmed COVID-19 and risk factors of a household member), presence of comorbidities (obstructive lung disease, seizures, congenital heart disease, Down's syndrome, and chronic kidney disease), signs and symptoms motivating the consultation, indication for hospitalization or outpatient follow-up, and clinical presentation. The length of stay was registered for hospitalized patients.

In relation to the operations of the Department of Pediatrics, 2019 and 2020 were compared to analyze outcome measures: number of outpatient visits, defined as those conducted in the outpatient emergency service; patients hospitalized in the general ward and in the intensive care unit due to seasonal conditions, defined as those caused by viruses with peak circulation in the autumn and winter; total beds available at the department; bed occupancy rate in the general ward and in the intensive care unit. In relation to medical and nursing staff, the cause of leave of absence, either due to pre-existing conditions or pregnancy, detectable COVID-19 or close contact with a COVID-19 patient were recorded.

\section{Ethical aspects}

The study was approved by the institutional Teaching and Research Committee.

Data were not used for other purposes than those described for their collection, and investigators protected the identity of data subjects through anonymization mechanisms.

\section{Statistical analysis}

Descriptive statistics were used to describe the population characteristics. Continuous outcome measures were expressed as median and interquartile range (IQR) because their distribution did not meet normality criteria. Categorical outcome measures were expressed as frequency and percentage.

Continuous outcome measures were compared using the Mann-Whitney test, whereas categorical ones were compared with the $\chi^{2}$ test. A value of $p<0.05$ was considered statistically significant. The strength of associations was described using an odds ratio (OR) and a $95 \%$ confidence interval $(\mathrm{CI})$.

The MS Excel 2010 ${ }^{\circledR}$ (Microsoft, Redmond, WA) and Stata ${ }^{\circledR}$, version 11 (StataCorp LLC, College Station, TX) software programs were used to record and analyze data.

\section{RESULTS}

Between March $12^{\text {th }}$ and August 31 $1^{\text {st }}, 2020$, a total of 5697 patients were tested at the facility because they were suspected cases; of these, 753 $(13.2 \%)$ were younger than 16 years. In addition, of these 753 cases, $152(20.2 \%)$ tested positive.

Figure 1 shows the flowchart of care for the pediatric population.

The median age of positive cases was 82 months (IQR: 20.5-147 months).

Also, $52.6 \%$ of patients were males $(80 / 152)$ and $15.13 \%$ of patients had a comorbidity (23/152).

A family member sharing the household who was positive for COVID-19 was an epidemiological link in $72.4 \%$ of cases $(110 / 152)$.

\section{Clinical manifestations}

Fever was the most common symptom in $123 / 152(81 \%)$, followed by respiratory symptoms (cough, odynophagia) in $85 / 152$ $(55.9 \%)$, neurological symptoms (headache) 
in $34 / 152(22.3 \%)$, and digestive symptoms (gastroenteritis) in 28/152 (18.4\%).

Figure 2 describes the most common symptoms in the general population.

\section{Hospitalization}

A total of 22/152 (14.47\%) patients required hospitalization due to an epidemiological reason or based on clinical criteria. No patient had a severe or critical course. All hospitalized children had a favorable course.

A total of $10 / 22(45.4 \%)$ patients were males.

The median age was 72.5 months (IQR: $31-95)$ in hospitalized patients and 85 months (20-148) in those managed as outpatients. This was not a statistically significant difference $(p=0.67)$.

The presence of a comorbidity was higher among patients who required hospitalization. In relation to hospitalized children, $9 / 22(40.9 \%)$ had a comorbidity, versus $14 / 130(10.9 \%)$ of those who were managed as outpatients $(p<0.001)$, OR: 5.74 (2.1-15.8).

The median length of stay was 5 days (IQR: 3-7).

Table 1 describes the clinical presentation based on the setting.

\section{Impact on the department's operations and} health care staff

Outpatient emergency service

This service has 5 walk-in offices that work as emergency areas, where 75295 patients sought care during 2019. ${ }^{11}$
In the first months of 2020, a crisis committee was established; it developed standardized protocols and implemented an interdisciplinary strategy to train staff on personal care behaviors and patient management.

FIGURE 1. Flowchart of suspected cases

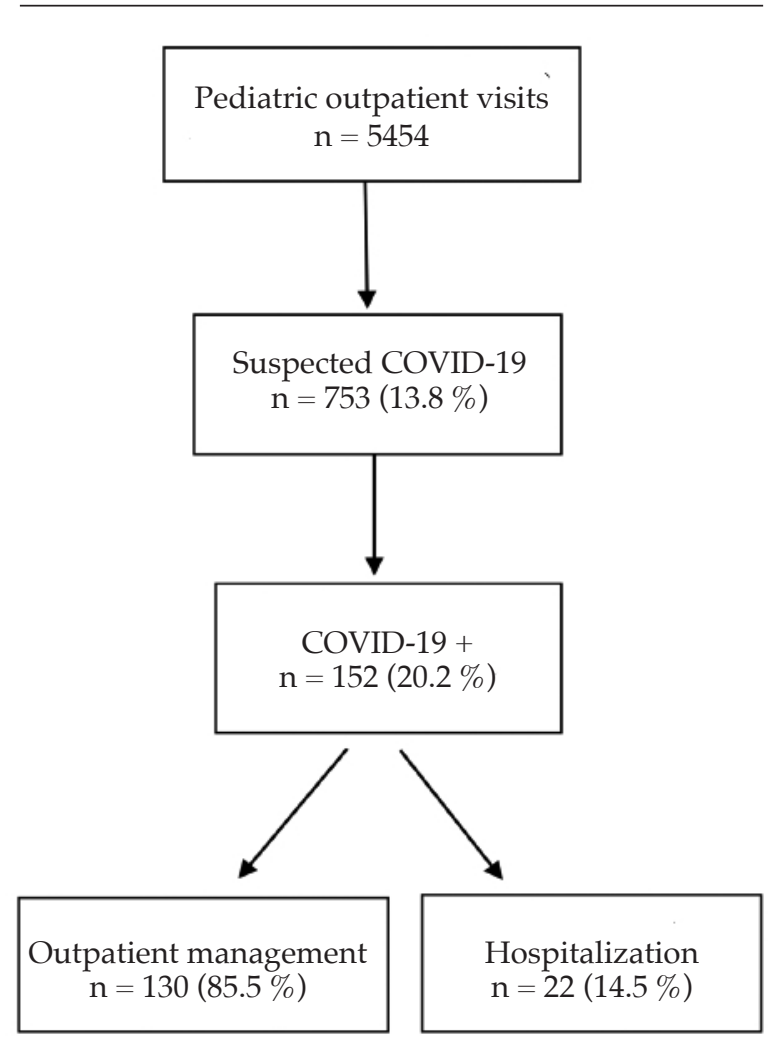

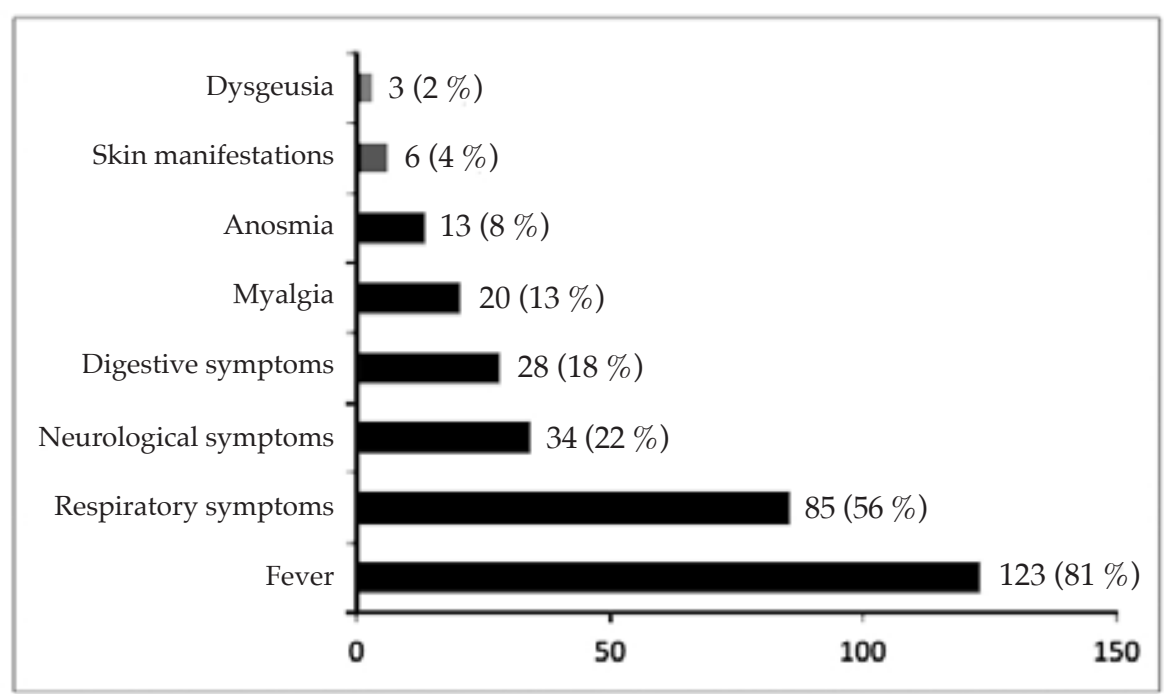


Each patient was assessed based on the biosafety recommendations made by the government authorities, so they underwent a complete clinical examination and ancillary tests, if necessary. Tests were done using a nasopharyngeal swab.

The treating team decided whether patients required hospitalization based on clinical criteria, such as oxygen requirement, intravenous antibiotic therapy or presence of comorbidities, or if it was possible to provide outpatient management based on the dynamic epidemiological recommendations made by the health authorities of the province of Buenos Aires. All cases were reported to the Argentine Integrated Health Care Information System (Sistema Integrado de Información Sanitaria Argentino, SISA).

In the case of patients managed as outpatients, their caregivers were contacted by telephone on a daily basis until they had an epidemiological discharge.

\section{Hospitalization ward}

In 2019, the bed occupancy rate was $78.48 \%$ (general pediatric ward) and $59.84 \%$ (pediatric intensive care unit [PICU]). In June, the bed occupancy rate showed a peak of $112.5 \%$ (children had to be hospitalized in other areas of the hospital) and $100 \%$, respectively. ${ }^{11}$
The hospitalization area, both the general ward and the PICU, was modified and 2 separate areas were established: COVID and Non-COVID, with medical and non-medical staff assigned to each one.

Any suspected patient referred from the outpatient emergency service was admitted to the COVID area based on their severity, and contact and droplet isolation was indicated. With nondetectable COVID-19 test results, patients were relocated to the non-COVID area, completed the hospitalization until meeting discharge criteria or were discharged home with the relevant epidemiological recommendations.

After hospital discharge, patient follow-up of confirmed cases was done over the telephone on a daily basis until epidemiological discharge.

As of June 2020, with the increase in adult cases, the space assigned to the pediatrics area, both in the outpatient emergency service and in the hospitalization area, decreased progressively. Three observation rooms in the outpatient emergency service and 10 rooms from the pediatric area were assigned to the emergency and the general medicine departments, respectively; 4 common rooms from the pediatric area were turned into PICUs; and the closed unit was restructured into a post-surgery recovery area for adult patients undergoing minor surgeries and discharged on the same day. Table 2 describes how the department operations were affected

TABLE 1. Clinical presentation by health care setting

\begin{tabular}{lccc}
\hline Symptoms & Hospitalization $(\mathbf{n}=\mathbf{2 2})$ & Outpatient $(\mathbf{n}=\mathbf{1 3 0})$ & $p$ \\
\hline Fever (n, \%) & $14(63.64)$ & $109(83.85)$ & 0.026 \\
Respiratory symptoms (n, \%) & $13(59.09)$ & $72(55.38)$ & 0.746 \\
Neurological symptoms (n, \%) & $4(18.18)$ & $30(23.08)$ & 0.61 \\
Digestive symptoms (n, \%) & $1(4.55)$ & $27(20.77)$ & 0.069 \\
Myalgia (n, \%) & $2(9.09)$ & $18(13.85)$ & 0.542 \\
Anosmia (n, \%) & $0(0.00)$ & $13(10.00)$ & 0.12 \\
Skin manifestations (n, \%) & $1(4.55)$ & $5(3.85$ & 0.87 \\
Dysgeusia (n, \%) & $0(0.00)$ & $3(2.31)$ & 0.472 \\
\hline
\end{tabular}

TABLE 2. Impact on the operations of the Department of Pediatrics

\begin{tabular}{|c|c|c|}
\hline Outcome measure & $\begin{array}{c}2019 \\
\text { (March 12 }{ }^{\text {th }} \text {-August 31 }{ }^{\text {st }} \text { ) }\end{array}$ & $\begin{array}{c}2020 \\
\text { (March } 12^{\text {th }} \text {-August 31 }{ }^{\text {st }} \text { ) }\end{array}$ \\
\hline No. of outpatient visits & 42456 & 5386 \\
\hline Patients hospitalized at the PICU due to a seasonal condition & 45 & 0 \\
\hline Patients hospitalized at the pediatric ward due to a seasonal condition & 101 & 0 \\
\hline Total beds available & 44 & 20 \\
\hline Bed occupancy rate in the general ward (\%) & 83.86 & 48.57 \\
\hline Bed occupancy rate in the PICU (\%) & 78.23 & 22.77 \\
\hline
\end{tabular}


during the study period compared to the same period of 2019.

During the study period, part of the health care team took a leave for different reasons, which resulted in greater staff absenteeism.

In addition, 2 out of 3 pediatricians from the outpatient emergency service witnessed an increment in their tasks, which now included the performance of nasopharyngeal swab tests in adult patients and filling in epidemiological cards.

Table 3 shows the total number of health care staff, their leaves, and the reasons.

\section{DISCUSSION}

Our study describes the clinical and epidemiological characteristics of more than 150 children diagnosed with SARS-CoV-2 infection, in whom a strict, daily telephone follow-up was done for clinical control, epidemiological surveillance, and family support until discharge. To our knowledge, this is the first report of a series of patients seen and followed at a private facility located in the AMBA.

Out of all suspected patients tested for COVID-19 at the hospital, only $13.2 \%$ were pediatric patients, which is consistent with what has been observed in other countries, where a smaller number of COVID-19 cases were also registered in the pediatric population ${ }^{12,13}$ and they also showed a less severe clinical presentation.

Most affected children had mild symptoms. The most common ones were fever, respiratory symptoms, such as cough and odynophagia, and neurological symptoms, such as headache. This is consistent with what has been reported in other publications, which showed that the pediatric population seemed to have fewer symptoms and a less severe course, with a much lower case fatality rate compared to adults. 13,14

In our series, less than $15 \%$ of children required hospitalization and no severe course or deaths were noted.

The initiation of the pandemic in Asia and its rapid spread to Europe allowed to observe the steep rise in the number of cases and its tragic consequences in those regions. ${ }^{4}$ In Argentina, in mid-March, such circumstances allowed the national and provincial governments to adopt harsh measures, such as closing down all educational institutions and establishing mandatory mask use and a strict preventive and mandatory social isolation policy with different stages and varying degrees of compliance. ${ }^{15}$

Such unprecedented and exceptional situation had a great impact on the operations and functioning of the hospital's Department of Pediatrics.

Unlike other years, practically no seasonal acute lower respiratory tract infections caused by other viruses were detected, especially respiratory syncytial virus. Actually, in the study period, no child was hospitalized in our facility due to bronchiolitis. In addition, the bed occupancy rate decreased by $42 \%$ in the general ward and $71 \%$ in the PICU.

In the Pediatric Emergency sector, outpatient visits decreased by $87 \%$ compared to 2019 , and appointments with specialists and clinicians were canceled for the first months and were then slowly scheduled again.

Most likely, the reasons behind such sudden decline in the number of visits and hospitalizations are the closure of schools, kindergartens, and infant care centers, which has been in force to date, mandatory mask use, hand washing or using alcohol-based hand gel, social distancing measures, fear of becoming sick, lack of resources to go from one place to another, and restricted access to medical consultations.

As the pandemic advanced and the number of adult patients with COVID-19 increased, it was necessary for pediatricians to start working along emergency physicians and to include performing nasopharyngeal swab tests in adult patients and filling in epidemiological cards as part of their routine tasks. In addition, the space assigned to pediatric hospitalizations, especially in the PICU, was gradually reduced, and pediatric nurses and intensivists had the latent possibility of taking charge of the critically ill adult population. This has been observed in local and international facilities. ${ }^{16,17}$

TABLE 3. Health care staff on leave

\begin{tabular}{lcc}
\hline Reason for leave & Medical staff $(\mathbf{n}=\mathbf{1 0 3})$ & Nursing staff $(\mathbf{n}=\mathbf{6 9})$ \\
\hline Pregnancy or pre-existing condition $(\mathrm{n}, \%)$ & $9(8.7)$ & $7(10.14)$ \\
COVID-19 + $(\mathrm{n}, \%)$ & $11(10.67)$ & $12(17.4)$ \\
Isolation due to close contact with COVID-19 patient $(\mathrm{n}, \%)$ & $39(37.86)$ & $13(18.84)$ \\
\hline
\end{tabular}


During the study period, no case of multisystem inflammatory syndrome in children was reported, as was the case in other publications. Such emergency situation is a warning that pediatric teams cannot overlook. ${ }^{18}$

Health care workers have been one of the segments most affected by the pandemic. Having multiple jobs is a constant condition among health care workers. More than half of physicians and one third of nurses were affected at some point during the study period. In some cases, they took a leave due to pregnancy, a pre-existing condition or COVID-19, while others were isolated because they were a close contact of a COVID-19 patient. This is consistent with what has been observed and published by other authors. ${ }^{19-21}$

The secondary effect of absenteeism is highly significant at a time when human resources are critical to meet the health care demand.

To date, our team, together with the different specialists, have managed to adapt to the pandemic in an unprecedented manner and is still adjusting several strategies to provide a better quality of care to pediatric patients.

We may conclude that most clinical forms observed in pediatrics were mild and the most common sign was fever. The department operations were considerably affected in terms of human resources. It is worth noting that the department requires to establish a logistic organization and develop health care protocols to face the COVID-19 pandemic.

\section{Acknowledgments}

We would like to thank Néstor Vain, M.D., for promoting the development of this study and making a critical reading; Norma Rossato, M.D., for her suggestions and educational attitude; and all the members of the health team of the Department of Pediatrics, health care providers and non-medical staff, for their unwavering commitment and silent work.

\section{REFERENCES}

1. Liu W, Zhang Q, Chen J, Xiang R, et al. Detection of COVID-19 in Children in early January 2020 in Wuhan, China. N Engl J Med. 2020; 382(14):1370-1.

2. Zimmermann $P$, Curtis N. Coronavirus infections in children including COVID-19: an overview of the epidemiology, clinical features, diagnosis, treatment and prevention options in children. Pediatr Infect Dis J. 2020; 39(5):355-68.

3. Argentina. Ministerio de Salud. Alerta epidemiológica. Información sobre nuevo coronavirus circulante. 2020, SE 04. [Accessed on: August $\left.7^{\text {th }}, 2020\right]$. Available at: https: / / www.argentina.gob.ar / sites / default / files / 20200123 coronavirus-alerta-epidemiologica-argentina.pdf
4. Rearte A, Baldani AEM, Barcena Barbeira P, Domínguez CS, et al. Características epidemiológicas de los primeros 116974 casos de COVID-19 en Argentina, 2020. Rev Argent Salud Publica. 2020;12 (Supl COVID-19):e5.

5. Argentina. Ministerio de Salud. Nuevo coronavirus COVID-19. Informe diario 09/03/2020.2020. [Accessed on: August $7^{\text {th }}$, 2020]. Availableat:https: / / www.argentina.gob. ar/coronavirus/informes-diarios/reportes / marzo2020

6. World Health Organization. Coronavirus disease (COVID-19) Weekly Epidemiological Update and Weekly Operational Update. Situation reports 51. 11/03/2020. [Accessed on: August $\left.7^{\text {th }}, 2020\right]$. Available at: https: / / www. who.int/emergencies/diseases / novel-coronavirus-2019/ situation-reports

7. World Health Organization. Coronavirus disease (COVID-19) Weekly Epidemiological Update and Weekly Operational Update. Situation reports 20/10/2020. [Accessed on:October $\left.20^{\text {th }}, 2020\right]$. Availableat:https: / / www. who.int/emergencies / diseases / novel-coronavirus-2019/ situation-reports

8. Argentina. Ministerio de Salud. Nuevo coronavirus COVID-19. Informe diario. 20/10/2020. 2020. [Accessed on: October $\left.20^{\text {th }}, 2020\right]$. Available at: https://www. argentina.gob.ar/coronavirus / informes-diarios / reportes/octubre2020

9. Buenos Aires. Ministry of Government. Special Projects Unit for AMBA. [Accessed on:June 29th, 2021. Available at: https: / / www.buenosaires.gob.ar/gobierno/unidades $\% 20$ de $\% 20$ proyectos $\% 20$ especiales $\% 20 \mathrm{y} \% 20$ puerto / que-esamba.

10. Argentina. Ministerio de Salud. Nuevo coronavirus COVID-19. Información epidemiológica. Sala de situación coronavirus online. Informe 20/10/2020. 2020. [Accessed on: October $\left.20^{\text {th }}, 2020\right]$. Available at: https://www. argentina.gob.ar/salud / coronavirus-COVID-19/ salasituacion

11. Sanatorio de la Trinidad Ramos Mejía. Estructura del Sanatorio. Servicio de Pediatría. Argentina 2020. [Accessed on: August 31 st, 2020]. Available at: http:// www.trinidadramosmejia.com.ar/Pages/Estructura-delSanatorio.aspx

12. Ong JSM, Tosoni A, Kim Y, Kissoon N, et al. Coronavirus disease 2019 in critically ill children: a narrative review of the literature. Pediatr Crit Care Med. 2020; 21(7):662-6.

13. Chen ZM, Fu JF, Shu Q, Chen YH, el al. Diagnosis and treatment recommendations for pediatric respiratory infection caused by the 2019 novel coronavirus. World J Pediatr. 2020; 16(3):240-6.

14. Taffarel P, Jorro Barón F. El paciente pediátrico crítico con COVID-19. Puesta al día. Arch Argent Pediatr. 2020; 118(5):e454-62.

15. Argentina. Decreto $297 / 2020$. Aislamiento social preventivo y obligatorio. Boletín Oficial de la República Argentina. Ciudad de Buenos Aires 19 de marzo de 2020. [Accessed on: August31 ${ }^{\text {st }}$,2020].https: / / www.boletinoficial.gob.ar/ detalleAviso/primera/227042/20200320

16. Vázquez Martínez JL, Alonso García R. Adaptación de una UCI pediátrica a Unidad de Adultos Críticos durante la pandemia COVID-19. An Pediatr (Barc). 2020; 93(3):216-7.

17. Christian M, Kissoon N. Caring for critically Ill adults in PICUs is not "Child's Play". Pediatr Crit Care Med. 2020; 21(7):679-81.

18. Feldstein L, Rose E, Horwitz S, Collins J, et al. Multisystem Inflammatory Syndrome in U.S. Children and Adolescents. N Engl J Med. 2020; 383(4):334-46.

19. CDC COVID-19 Response Team. Characteristics of Health Care Personnel with COVID-19 -United States, February 12-April 9, 2020. MMWR Morb Mortal Wkly Rep. 2020; 
316 / Arch Argent Pediatr 2021;119(5):310-316 / Original article

69(15):477-81.

20. Ng K, Poon BH, Kiat Puar TH, Shan Quah J, etal. COVID-19 and the Risk to Health Care Workers: a case report. Ann Intern Med. 2020; 172(11):766-7.
21. Sim MR. The COVID-19 pandemic: major risks to healthcare and other workers on the front line. Occup Environ Med. 2020; 77(5):281-2. 